\title{
The Effect of Zero Balance Ultrafiltration of Priming Blood on Clinical Outcomes of Infants Undergo Cardiopulmonary Bypass
}

\author{
Maziar Gholampour Dehaki', Rasoul Azarfarin², Hooman Bakhshandeh ${ }^{3}$, Mohammad Mahdavi, \\ Azin Alizadehasl ${ }^{5}$, Sana Niknam ${ }^{6,7 *}$, Azadeh Niknam ${ }^{8}$ \\ 1. MD Professor, Department of Pediatric Cardiac Surgery, Rajaie Cardiovascular Medical and Research Center, Iran University of \\ Medical Sciences, Tehran, Iran \\ 2. Professor, Department of Anesthesiology, Rajaie Cardiovascular Medical and Research Center, Iran University of Medical \\ Sciences, Tehran, Iran \\ 3. Assistant Professor, Department of Epidemiology and Biostatistics, Rajaie Cardiovascular Medical and Research Center, Iran \\ University of Medical Sciences, Tehran, Iran \\ 4. Assistant Professor, Department of Pediatric Cardiologist, Rajaie Cardiovascular Medical and Research Center, Iran University \\ of Medical Sciences, Tehran, Iran \\ 5. Assistant Professor, Department of Cardiology, Rajaie Cardiovascular Medical and Research Center, Iran University of Medical \\ Sciences, Tehran, Iran \\ 6. Perfusion Chief Technician, Department of Clinical Research Development, Besat Hospital, Hamadan University of Medical \\ Sciences, Hamadan, Iran \\ 7. Rajaie Cardiovascular Medical and Research Center, Iran University of Medical Sciences, Tehran, Iran \\ 8. BSN, Department of Pediatric Nursing, Faculty of Nursing and Midwifery, Kurdistan University of Medical Sciences, Sanandaj, \\ Iran
}

\section{\begin{tabular}{lr}
\hline \multicolumn{2}{c}{ Article Info } \\
\hline & \\
Received: & $2018 / 05 / 04$ \\
Accepted: & $2018 / 06 / 09$ \\
Published Online: & $2019 / 05 / 22$
\end{tabular}}

DOI: $10.30699 /$ sjhnmf.27.2.107

Original Article

Use your device to scan and read the article online

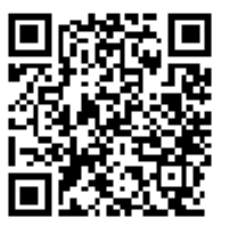

\section{Abstract}

Introduction: Pediatric Cardiopulmonary Bypass (CPB) circuit invariably requires priming with Packed Red Blood Cells (PRBCs). Metabolic composition of stored PRBCs is unphysiological. Commencement of PRBC primed CPB leads to rapid transfusion of massive metabolic load. This predisposes pediatric patients to the risk of complications such as electrolyte disturbances, citrate toxicity, acidosis and activation of the inflammatory response. The aim of this study is to evaluate the effect of ultrafiltration of priming blood on clinical outcomes infants undergo cardiopulmonary bypass.

Methods: This was a clinical trial, with two groups (intervention and control) and a sample of 60 infants referred to Shahid Rajaie Hospital in Tehran (30 patients in intervention and 30 patients in control group) that was carried out in 2017. Ultrafiltration was used on prime with Conventional Ultrafiltration (CUF) for patients in the intervention group during $\mathrm{CPB}$, but in the control group only CUF was used. Arterial blood gas parameters, amount of bleeding, blood transfusion rate, the duration of mechanical ventilation, residence in the ICU and the level of electrolytes were measured. Data of this study was analyzed using the Chi-square test, T- test Independent-Sample, Repeated-measure, Mann Whitney U test by SPSS 25.

Results: In terms of electrolytes, the prime solution used in the intervention group was significantly closer to physiological comparing to the control group $(P<0.05)$. The intervention group showed significant reductions in postoperative blood loss; postoperative blood transfusion; time to extubation; the length of stay in the ICU; $(P<0.05)$. The level of electrolytes and other parameters of arterial blood gas were similar in both groups.

Conclusions: It can be concluded that the combination of the ultrafiltration of priming blood and CUF method effectively reduces the side effects of cardiopulmonary bypass.

Keywords: Cardiopulmonary Bypass, Ultrafiltration, Infants
Corresponding Information
Sana Niknam, Department of Education, Rajaie Cardiovascular Medical and Research Center, Iran University of Medical Sciences, Tehran, Iran. Email: niknam82@yahoo.com

Copyright (C) 2019, This is an original open-access article distributed under the terms of the Creative Commons Attribution-noncommercial 4.0 International License which permits copy and redistribute of the material just in noncommercial usages with proper citation.

How to Cite This Article: 


\section{مجلهُ مراقبت يرستارى و مامايى ابن سينا - شايا الكترونيك: بو

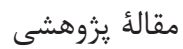

بررسى تأثير اولترافيلتراسيون به روش زيروبالانس يرايم خونى بر ييامدهاى بالينى در شيرخوارن تحت

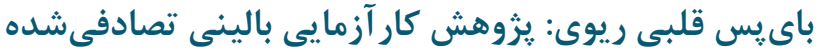

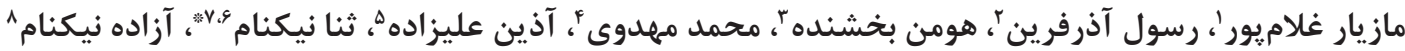

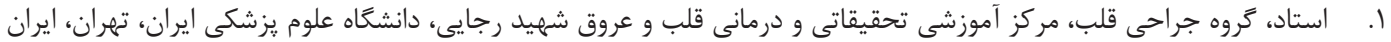

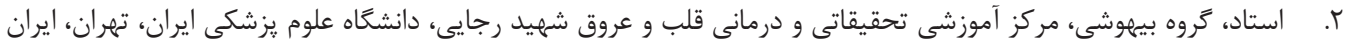

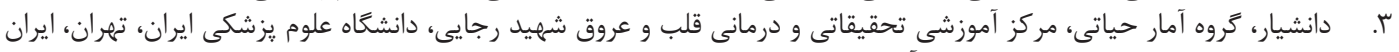

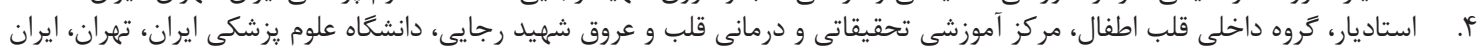

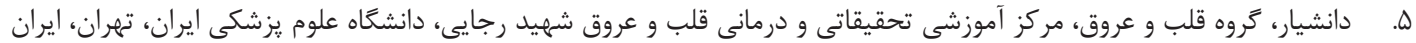

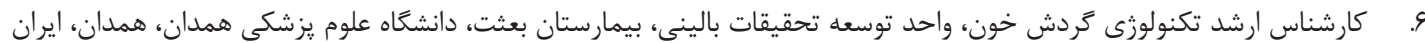

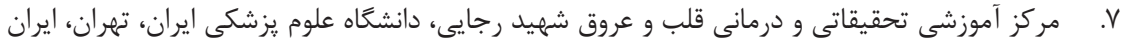

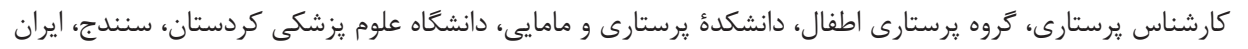

جكيده

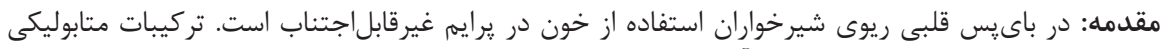

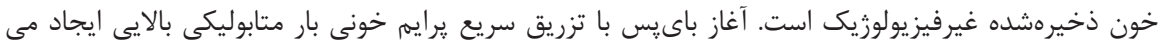

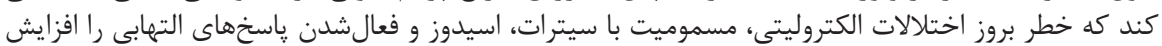

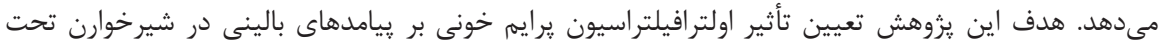
باى يس قلبى ريوى است.

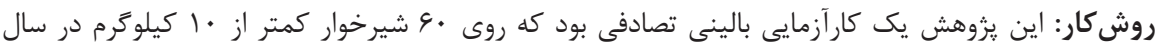

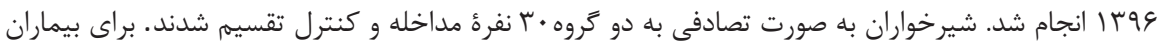

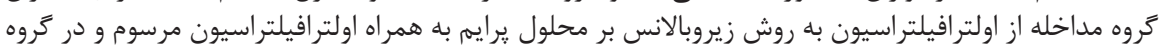

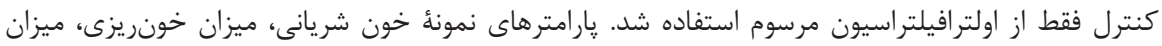

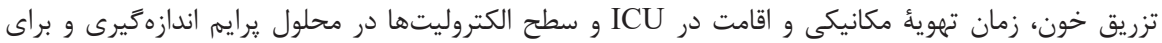

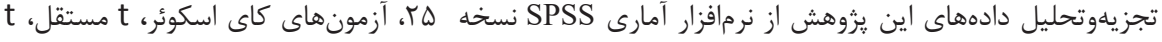

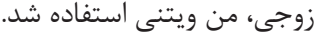

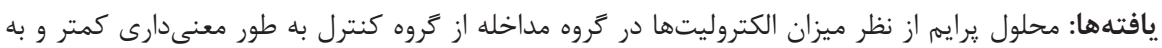

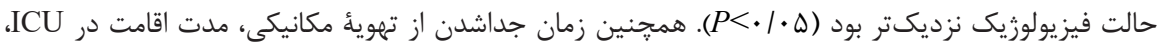

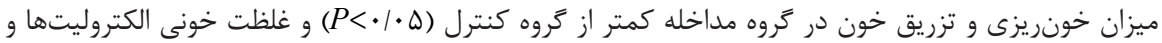

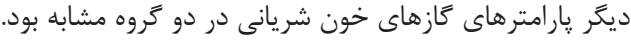

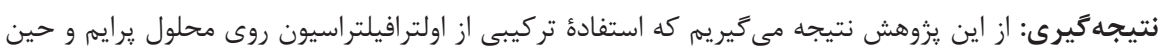

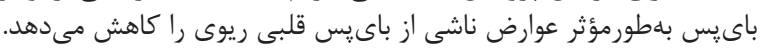

كليدوازهها: كارديو يولمونرى باى يس، الترافيلتراسيون، شيرخواران بانس

اطلاعات مقاله - - اله

\begin{abstract}
تاريخ وصول:
تاريخ يذيرش:

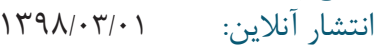

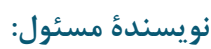

ثنا نيكنام

كارشناس ارشد تكنولورى كردش خون، واحد توسعه تحقيقات بالينى، ارني،

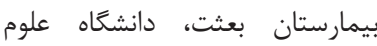
يزئشى همدان، همدان، ايران
\end{abstract}

يست الكترونيك: niknam82@yahoo.com

مقدمه

نقايص مادرزادى قلب در شيرخواران و اطفال ضرورى است. در شيرخواران اختلاف اندازءٔ مدار باىيس قلبى دئ ريوى نسبت به بدن بيمار بيشتر از بالغين است، حتى حداقل حجم محلول يرايم اغلب بيشتر از حجم خون بيمار است. به همين دليل براى حفظ هماتوكريت در طول باىيس قلبى رئى ريوى'

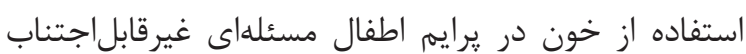
است [F]. از طرفى خون ذخيرهشده حاوى سايتوكنينهاى التهابى، مواد نتَهدارندهُ يك سل، شامل سيترات، فسفات و و

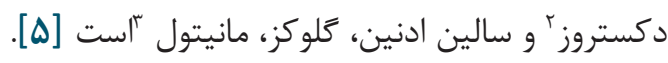

1. Cardiopulmonary Bypass (CPB)

2. Citrate-Phosphate-Dextrose (CPD)

3. Saline-Adenine-Glucose-Mannitol (SAGM)
باى يس قلبى ريوى براى ترميم يا تسكين بسيارى از نقايص

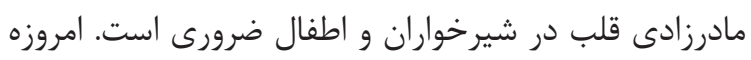
در جراحى قلب اطفال به ترميم نقايص قلبى مادرزادى، قبل از آنكه قلب و بدن بيمار سازگًارى مخرب با فيزيولوزى

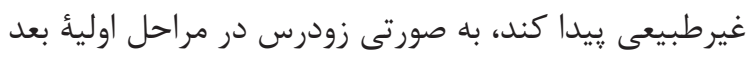

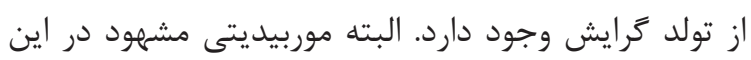

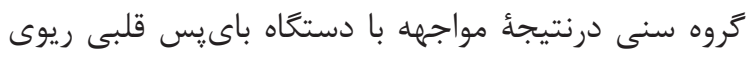

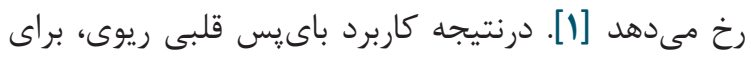

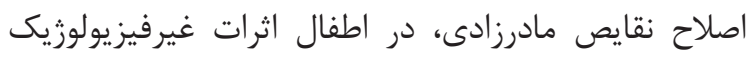

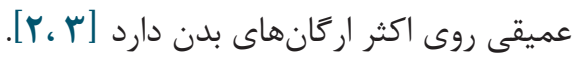
باى يس قلبى ريوى براى ترميم يا تسكين بسيارى از 
و اصلاح الكتروليتها يزوهشگران يزوهشى با هدف تعيين تأثير اولترافيلتراسيون محلول گرايم به روش Zero-balance بر رِيامدهاى بالينى شيرخواران تحت عمل جراحى باىيس قلبى ريوى انجام دادند.

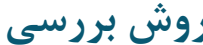

اين :ززوهش كارآزمايى بالينى است كه در بيمارســتان قلب

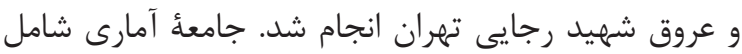
همةٔ شيرخواران و نوزادانى است كه براى انجام عمل قلب باز،

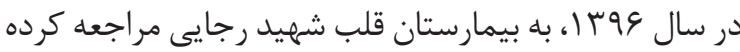
بودند. يس از كسب مجوز از كميتهٔ اخلاق بيمارستان قلب رجايى و اخذ رضايتنامئ آتاهانه و آزادانه از والدين بيماران • نفر از شيرخواران كمتر از ده كيلوگرم كه با تشخيص نقص قلبى مادرزادى تحت عمل جراحى قلب قرار گرفتهاند با تصادفىسازى به روش balance Block Randomization

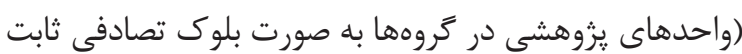

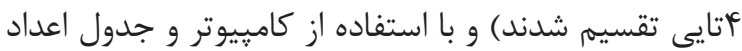
تصادفى ترتيب ورود نمونهها در گروهها مشخص شد. سيس به دو گروه • انفرهٔ مداخله و كنترل تقسيم شدند. با استفاده از فرمول زير حجم نمونه به دست آمد:

$$
n=\frac{2\left(z_{1-\frac{\alpha}{2}}+z_{1-\beta}\right)^{2} \times s^{2} p}{\left(\mu_{1}-\mu_{2}\right)^{2}}
$$$$
\alpha=0.05 \quad \mu_{1}=0.78 \quad \mu_{2}=1.23
$$

$$
s_{1}=0.59 \quad s_{2}=0.48
$$

ميانگين ايندكس تنفسى در زروه كنترل

ميانگين ايندكس تنفسى در زروه مداخله

$\beta=\cdot / r$

معيارهاى ورود به يزوهش شامل داشتن دوره باردارى بيش از TV هفته، رضايتنامة آكاهانه والدين بيمار، وزن كمتر از • ا كيلوگرم، بيماران كانديد عمل جراحى قلب؛ و معيارهاى خروج از يزوهش شامل نارضايتى والدين بيمار براى حضور در يزوهش، بيمارى غيرقلبى فعال مؤثر

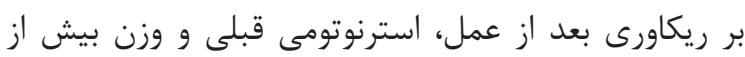

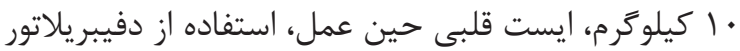

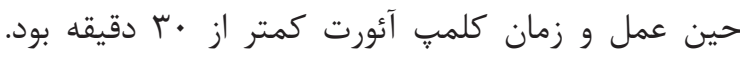
دادهها با استفاده ازيرسشنامهٔ اطلاعات دموكر افيك و سياهئ جمعآورى اطلاعات قبل و بعد از مداخله گردآروى شدند.

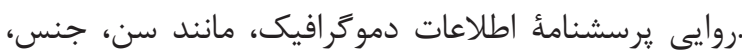

آغاز باى يس با تزريق سريع يرايم خونى، بار متابوليكى

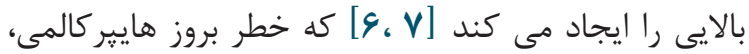
هايِرناترمى، هايير گلايسمى، مسموميت با سيترات، اسيدوز،

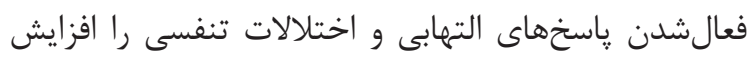

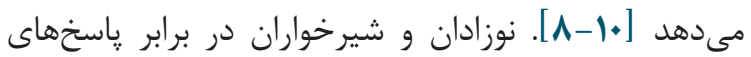
التهابى، به دليل نياز متابوليكى بالا، واكنش عروق ريوى و عملكرد اركانهاى نابالغ، آسيبزيذيرتر هستند. بنابراين كاهش مشكلات مربوط به خون براى بهترشدن نتايج بعد از CPB اهميت دارد. ترانسفوزيون خون سبب نارسايى اركانهاى مختلف بدن بعد از CPB مىشود، زيرا آنزيم

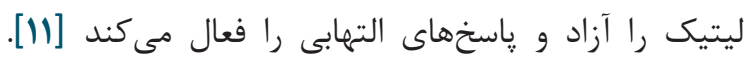

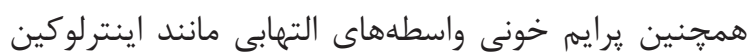
A و برادى كينين را آزاد مى كند [IIT].

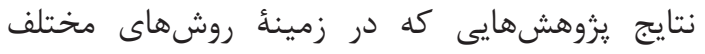
فيلتركردن محلول يرايم اطفال صورت گرفته نشان مى دهدي

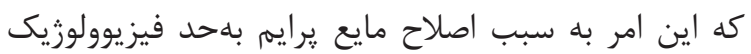

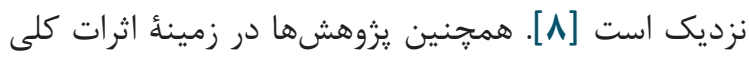
الترافيلتراسيون به مواردى مثل: كاهش خونريزى بعد از عمل، كاهش عوارض ريوى، كاهش زمان اتصال به دستعاه تهويةٔ مكانيكى، كاهش حجم ترانسفوزيون F اساعته بعد از

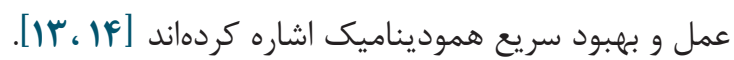

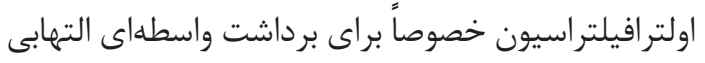
و متابوليكى و كاهش آب و آدم بافتى در كودكان بيشنهاد بردي شده است [1ه] و انجام آن در : يرايم اطفال مواد مضر در

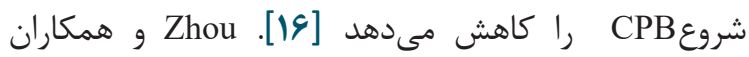

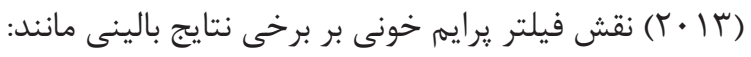

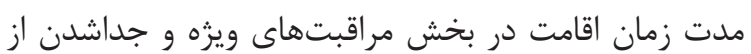

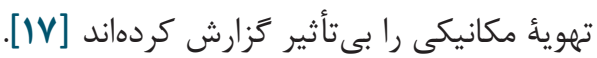

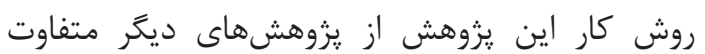
است. همجنين يزوهشى در زمينـ انجام زيروبالانس بر يرايم خونى با سرم هاف سالين انجام نشده است. فرضيئ ما اين است كه انجام اولترافيلتراسيون محلول يرايم خونى سطوح الكتروليتى محلول :يرايم و بهبود نتايج بالينى را اصلاح

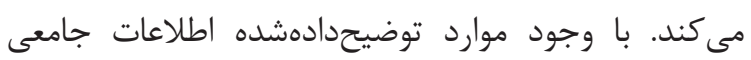
وجود ندارد كه بررسى ييامد استفاده از روش

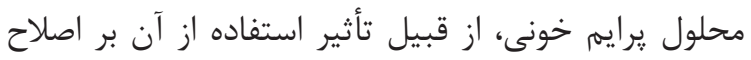

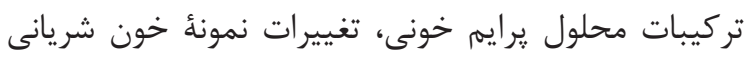

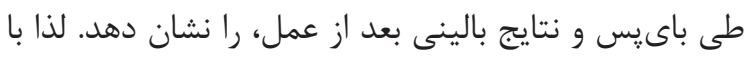
توجه به نقش Zero-balance در برداشت واسطه هاى التهابى 
(T2)، بعد از گرمكردن بيمار (T3) و يايان عمل (T4)، شامل HCT, Hb, BE, HCO3, Lactate, Bs, Cl, K, PH, Na دستخاه تكنومديا، ساخت كشور زاين، اندازمخيرى و لاكتات

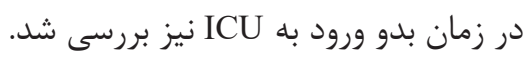

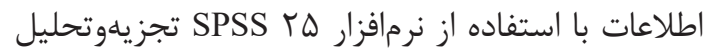
شد. براى توصيف مشخصات واحدهاى يزوهش در هر دو

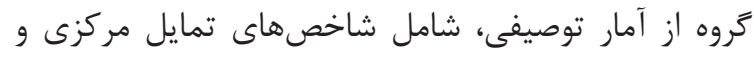

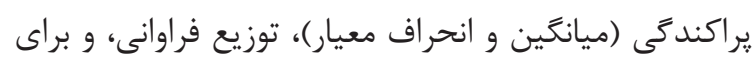

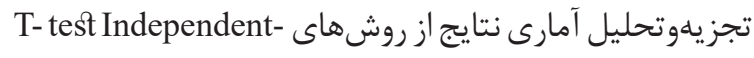
,Chi-square ANOVA Repeated-measure.Samples Mann Whitney U , در سطح معنى دارى كمتر از ه•/ استفاده شد.

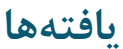

در اين يزوهش مشخصات دموكرافيك، شامل وزن، جنس،

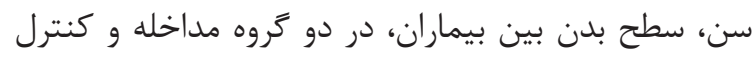

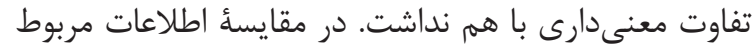

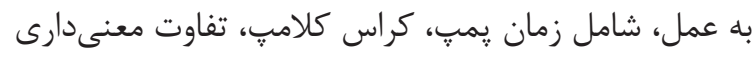

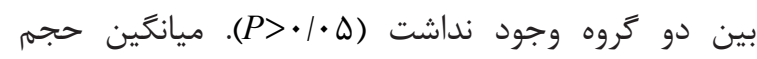
فيلتراسيون طى باى يس در گروه مداخله بو 19 ميلى ليتر و در كروه كنترل 119 ميلىليتر بود. همجنين بين مقدار حجمه

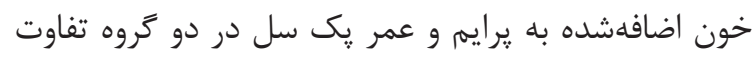

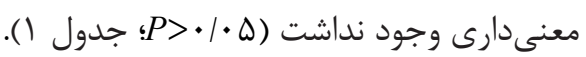
طبق جدول r محلول اولئ يرايم بلهور معنى دارى

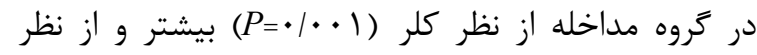

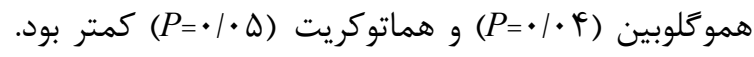

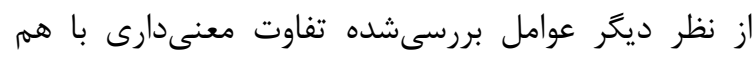

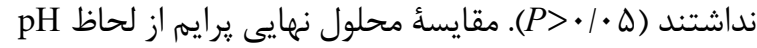
و الكتروليتها بين دو گروه نشان مىدهد كه الكتروليتها

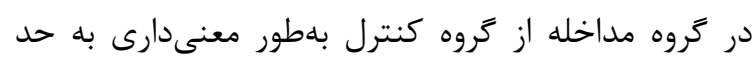

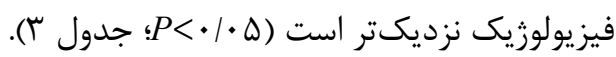
تغييرات هموكلوبين، هماتوكريت، سديم، يتاسيم، قند،

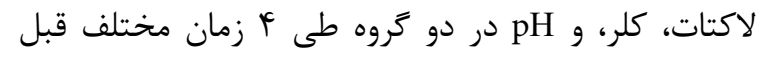

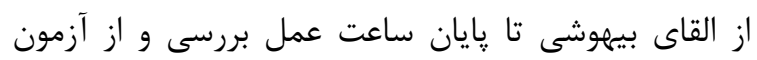

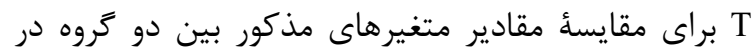

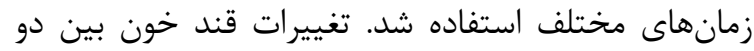

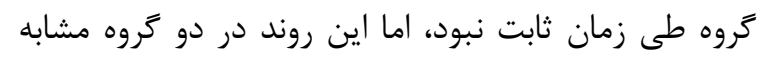

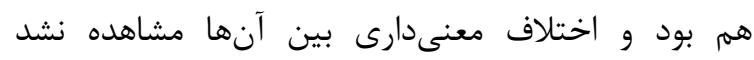
.$(P=\cdot / \cdot V)$ مقدار قند خون در زمانهاى بعد از كلامٍ آئورت در
وزن،' ، و سياهه را V نفر از اعضاى هيئت علمى بيهوشى و

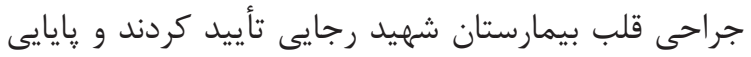

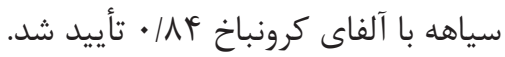

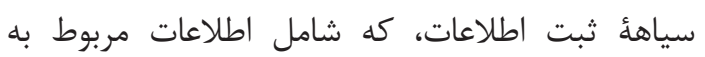
نتايج مداخله طى عمل و FF ساعت يس از آن بود، هنگام يزوهش تكميل، همأ شرايط بيهوشى و يمٍ باى يس براى

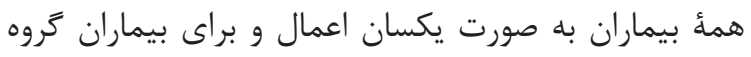

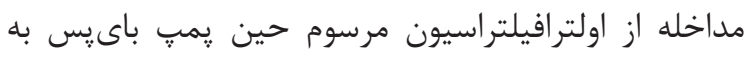
همراه اولترافيلتراسيون به روش زيروبالانس بر محلول يرايم

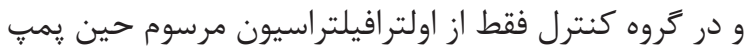

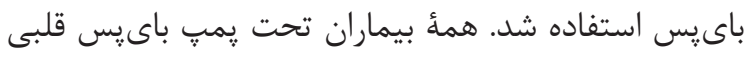

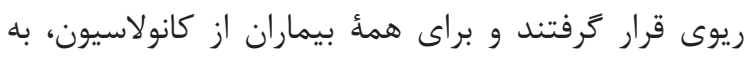
روش bicaval، استفاده شد. براى انجام مناسب عمل جراحى دماى بدن بيماران

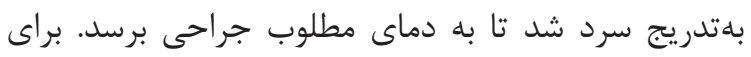

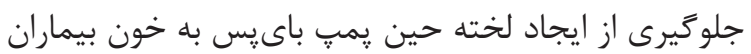

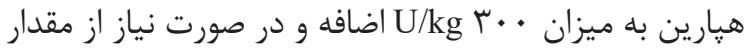

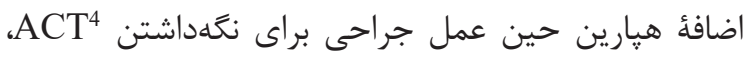

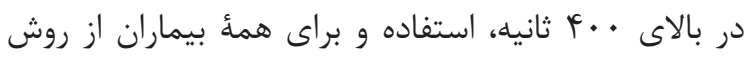

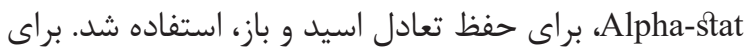
بيماران هر دو كروه از اولترافيلتراسيون مرسوم (ساخت

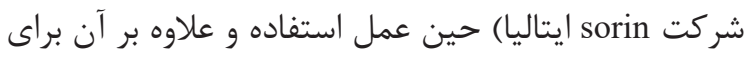

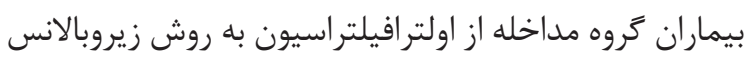
بر محلول يرايم (ساخت شركت sorin ايتاليا) قبل از باى يس ريس

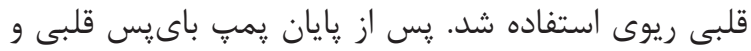

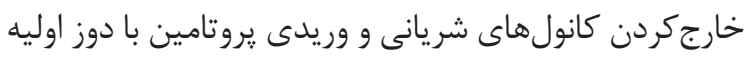

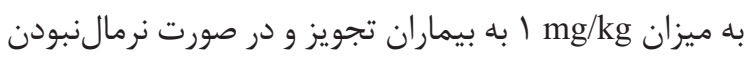
ACT دوزهاى بعدى نيز، با استفاده از فرمول (1)، تجويز شد.

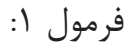

prime blood needed $(\mathrm{ml})=\frac{(\mathrm{PBV}+\text { circuit volume })(\text { desired bypass } \mathrm{Hct})-(\mathrm{PBV})(\text { patient Hct })}{\text { Hct of prime blood product }}$ PBV=Patient Blood Volume

مقدار خون لازم براى اضافه كردن به محلول يرايم محاسبه

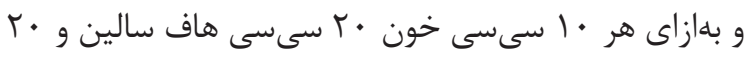
سىسى رينكر براى انجام زيروبالانس به مخزن وريدى اضافه

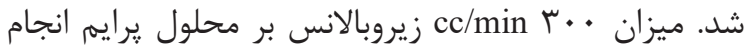

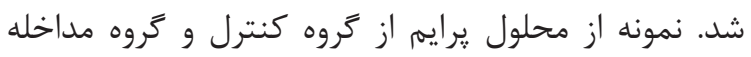

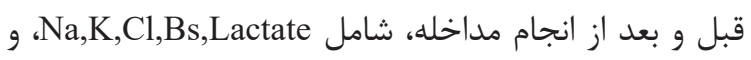

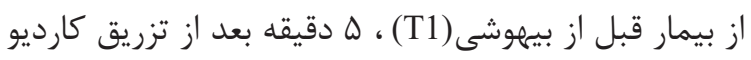

4. Activated Clotting Time 


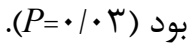

تغييرات سديم بين دو گروه طى زمان ثابت نبود و روند تغييرات كاهشى، سيس افزايشى بود و اين روند در دو گروه بهطور معنى دارى متفاوت بود. سديم در يايان عمل

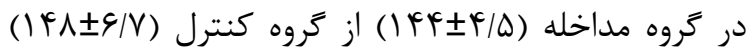
كمتر و به سطح فيزيولوزيك نزديكتر بود ( ( •|==P؛ شكل (1). مدت زمان تهويه مكانيكى، اقامت در بخش مراقبتهاى ويزه، ميزان خونريزى و تزريق خون در گروه مداخله بهطور

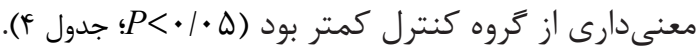

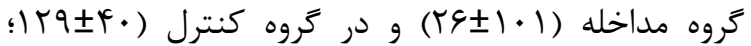

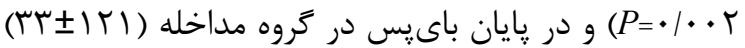
و گروه كنترل (d) داشت؛ به گَونهاى كه مقادير در گروه مداخله از گروه كنترل كمتر و به حالت فيزيولوزيك نزديكتر بود. تغييرات لاكتات بين دو گروه طى زمان ثابت نبود، اما اين روند در

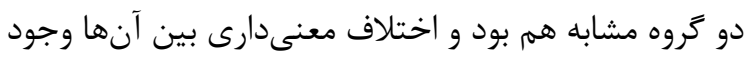

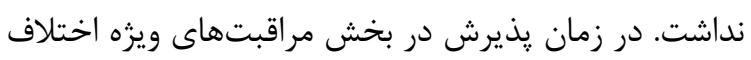
معنى دارى، از نظر لاكتات، بين گروهها وجود داشت و در

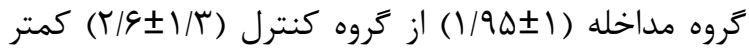

$$
\text { جدول ا. اطلاعات دموكر افيك مربوط به عمل در دو كروه مداخله و كنترل }
$$

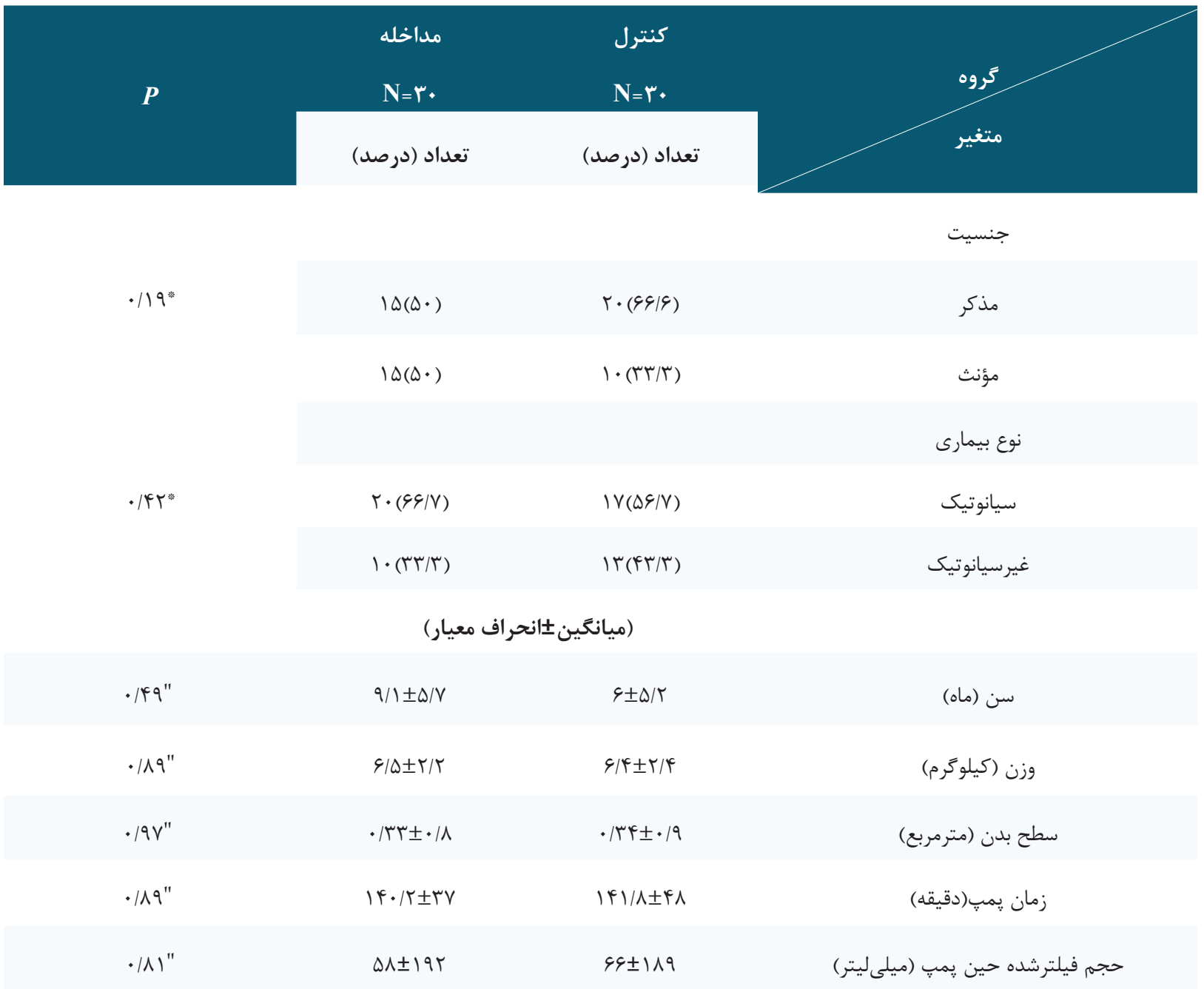

ميانه (جارك (VD-YD)

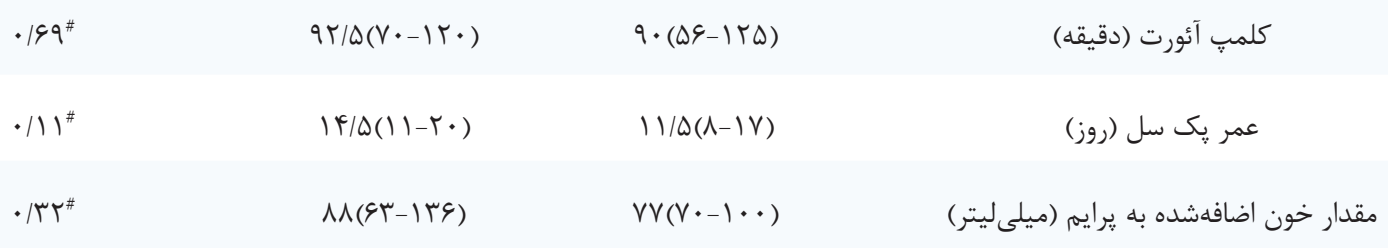

* Pearson Chi-square; " Independent sample t-test; \# Mann Whitney U Test 
جدول r. مقايسةٔ محلول اولية يرايم از لحاظ PH و الكتروليتها در دو كروه كنترل و مداخله

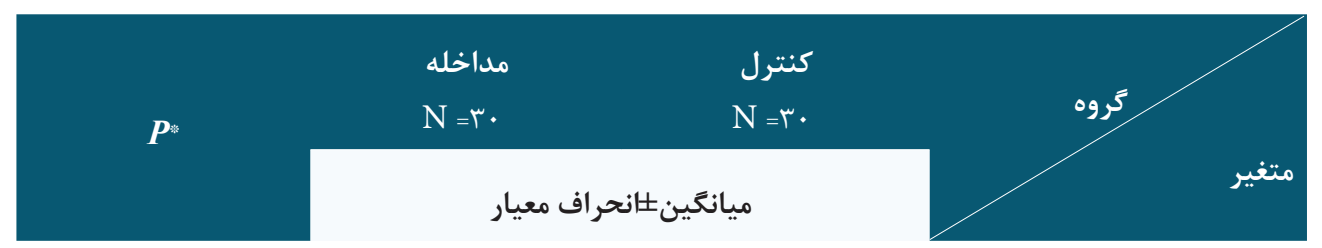

\begin{tabular}{|c|c|c|c|}
\hline$\cdot / \wedge 9$ & $V / \cdot r \pm \cdot|r|$ & $V / \cdot r \pm \cdot / r$ & $\mathrm{PH}$ \\
\hline.$/ 1 T$ & $\mid \Delta \varphi \pm V / V$ & $10 r / 9 \pm 9 / 9$ & $\mathrm{Na}(\mathrm{mEq} / \mathrm{L})$ \\
\hline$\cdot / 49$ & $9 / 9 \pm 1 / 9$ & $V / I r \pm 1 / \Delta \Delta$ & $\mathrm{K}(\mathrm{mEq} / \mathrm{L})$ \\
\hline $.1 \cdot .1$ & $\mid r r / 9 \pm 9$ & $\mid r \Delta / v \pm q / 1$ & $\mathrm{Cl}(\mathrm{mEq} / \mathrm{L})$ \\
\hline$\cdot / \Lambda \Lambda$ & $q \Delta / q \pm r F / V$ & $G V / r \pm r \cdot / r$ & $\mathrm{BS}(\mathrm{mg} / \mathrm{dl})$ \\
\hline.$/ 1 F$ & $\Delta / I T \pm \| / \varphi$ & $q / F \Delta \pm F / V$ & Lactate $(\mathrm{mmol} / \mathrm{l})$ \\
\hline$\cdot / \cdot F$ & $r / \wedge \Lambda \pm 1 / r$ & $\Delta /\{\wedge \pm 1 / \cdot r$ & $\mathrm{Hb}(\mathrm{g} / \mathrm{dl})$ \\
\hline$\cdot / \cdot \Delta$ & $10 / \mathcal{F} \pm r / q$ & $\mid \mathrm{V} / \Lambda \pm \Delta / \mathrm{T}$ & HCT (\%) \\
\hline
\end{tabular}

*Independent sample t-test

جدول ب. مقايسُٔ محلول نهايى برايم از لحاظ الكتروليتها در دو كروه كنترل و مداخله

\begin{tabular}{|c|c|c|c|}
\hline$P^{*}$ & $\begin{array}{l}\text { مداخله } \\
\text { N=r. }\end{array}$ & كنترل & كروه \\
\hline \multicolumn{4}{|c|}{ ميانغَين土انحراف معيار } \\
\hline$<\cdot / \cdot \cdot 1$ & $\mid r \omega / r \pm \varepsilon / \varepsilon$ & $1 \Delta r / 9 \pm 9 / 9$ & $\mathrm{Na}(\mathrm{mEq} / \mathrm{L})$ \\
\hline$<\cdot 1 \cdot \cdot 1$ & $F / r \pm \cdot / V$ & $V / I \pm 1 / \Delta$ & $\mathrm{K}(\mathrm{mEq} / \mathrm{L})$ \\
\hline$<\cdot / \cdot \cdot 1$ & $|r| / 9 \pm V$ & $|r \Delta / V \pm q /|$ & $\mathrm{Cl}(\mathrm{mEq} / \mathrm{L})$ \\
\hline$<\cdot \mid \cdot \cdot 1$ & $r q \pm r$. & $q V \pm r$. & $\mathrm{BS}(\mathrm{mg} / \mathrm{dl})$ \\
\hline$<\cdot / \cdot \cdot 1$ & $r \pm 1 / 1$ & $\varepsilon / 4 \pm \psi / \varphi$ & Lactate $(\mathrm{mmol} / \mathrm{l})$ \\
\hline
\end{tabular}

* Independent sample t-test

جدول F. مقايسةٔ اطلاعات مربوط به مدت يِيامدهاى بالينى بين دو تروه كنترل و مداخله

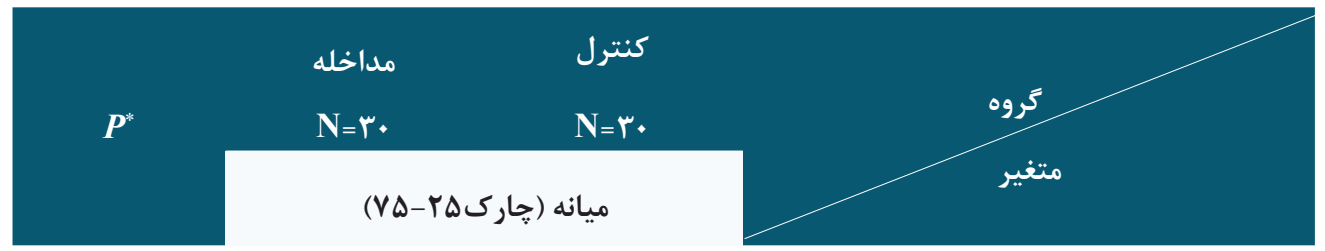

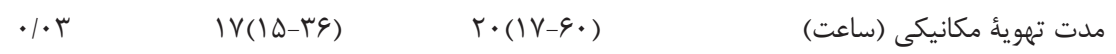

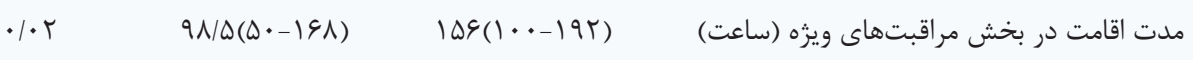

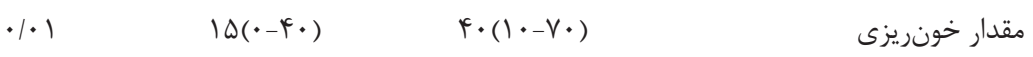

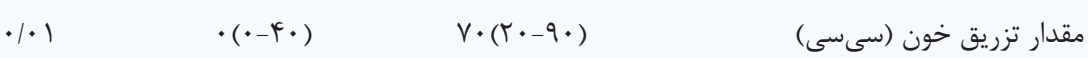

* Mann Whitney U Test 

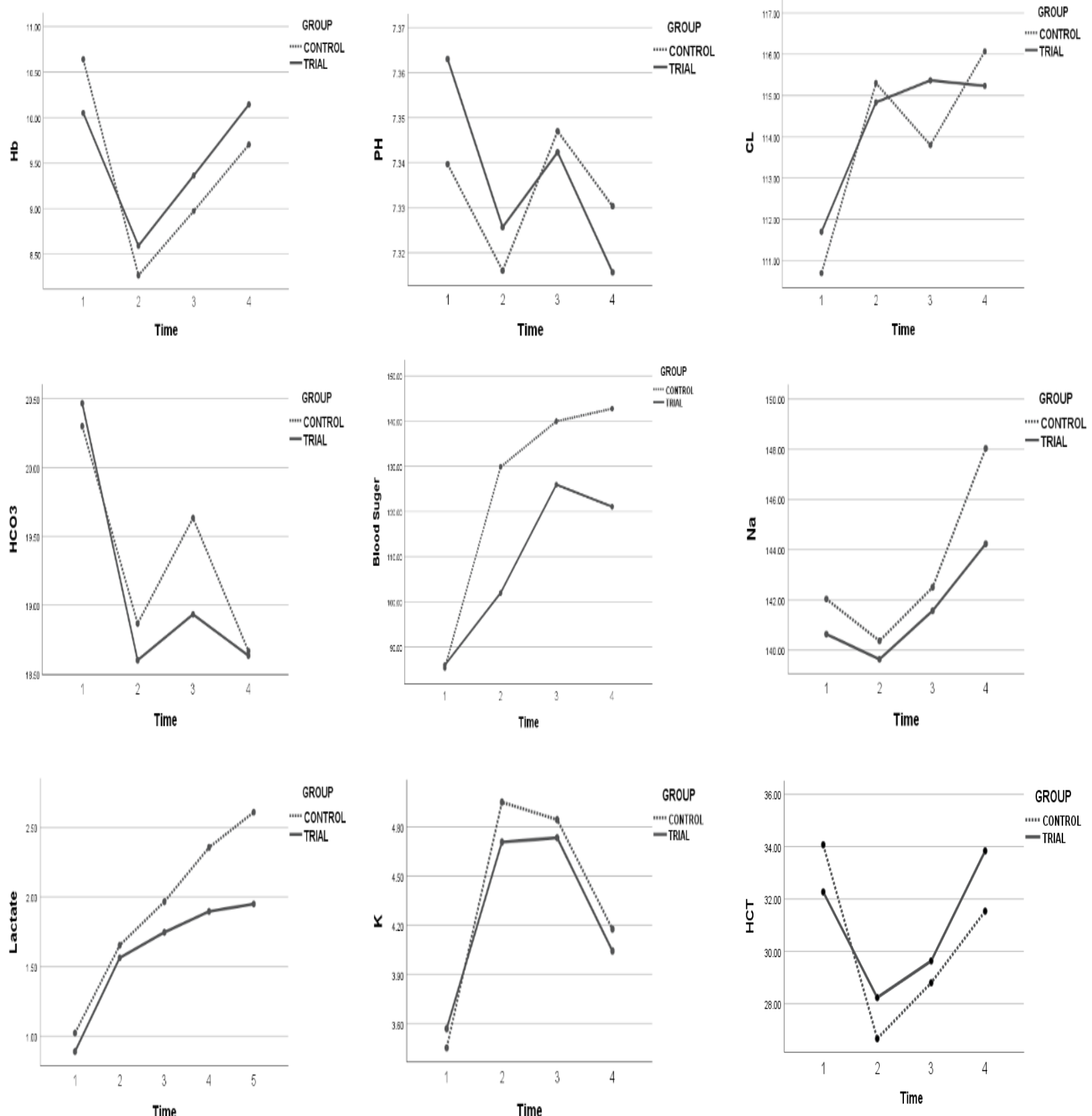

شكل ا. روند تغييرات شاخصهاى خون شريانى بيمار طى زمان در كروه مداخله و كنترل

به بر برسى اثرات بالينى يك روش تركيبى اولترافيلتراسيون

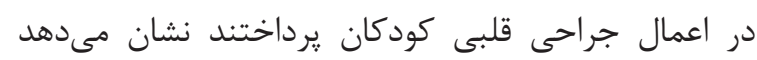
كلوكوز، لاكتات و TNF در محلول ثرايم كروه مداخله بهطور

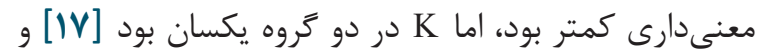

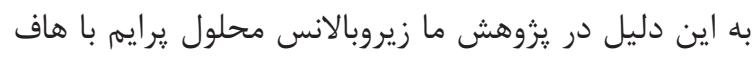

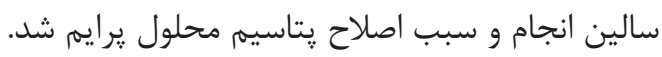
در يزوهش Ugaki و همكاران بلهنبال انجام فيلتر يرايم خونى، يتاسيه، لاكتات، سروتونين و اينترلوكين 1 در محلول

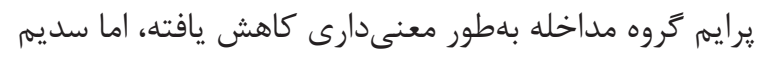

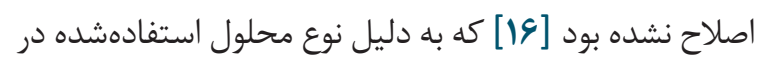
هدف اين يزوهش تعيين تأثير اولترافيلتراسيون يرايم

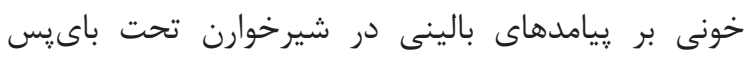

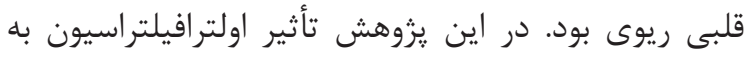

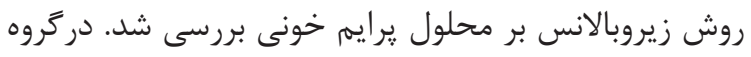

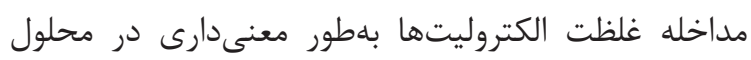

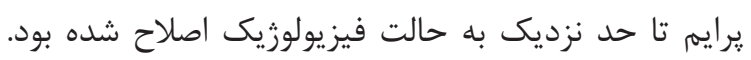

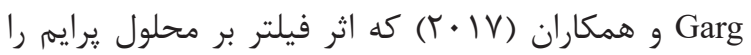

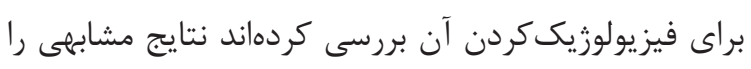

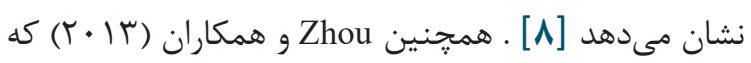




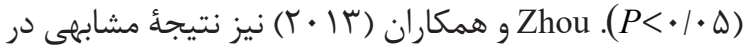
مورد قند خون و لاكتات در زمان مذكور به دست آوردهاند

از محدوديتهاى يزوهش حاضر مى توان به همكارى نكردن

والدين شيرخواران تحت باىيس قلبى ريوى در يزوهش، طولانىشدن انجام مراحل يزوهش، كوتاه بودن زمان بين يذيرش شيرخوار و آغاز باى يس قلبى ريوى اشاره كرد كه

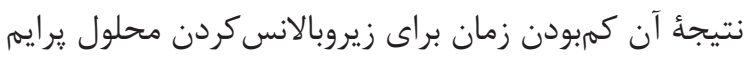

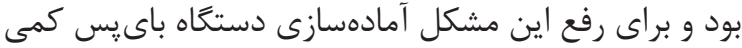
قبل از يذيرش بيمار در اتاق انجام ترفت.

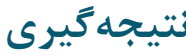

با توجه به حجم مشهود محلول يرايم نسبت به حجم در

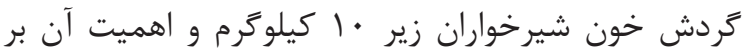
وضعيت پِ از عمل، كودكان كانديد عمل جراحى قلب باز، اصلاح محلول يرايم خونى ضرورى است. ما در اين يزوهش إنى نشان دادهايم استفاده از فيلتر روى محلول يرايم خونى صرولى عوارض ناشى از كارديويولمونرى باىيس را كم مى كند. بهكاركيرى نتايج اين يزوهش عوارض درمان و هزينهاي

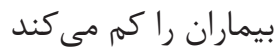

\section{سياسگزارى}

اين يزوهش بخشى از باياننامؤ كارشناسى ارشد كرايش

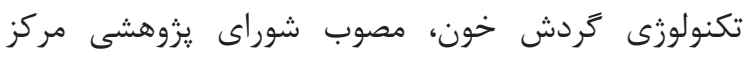
آموزشى تحقيقاتى و درمانى قلب و عروق شهيد رجايى

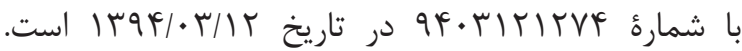
همجنين در كميتؤ اخلاق يزوهش در تاريخ كو با كد مصوب.RHC.AC.IR.REC 1396.49 تأييد و در مركز كارآزمايى بالينى با كد IRCT20180110038301N1 ثبت

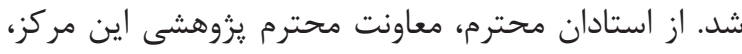

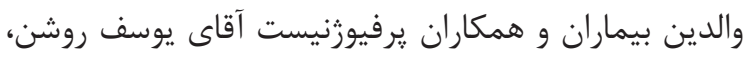
آقاى افشين حسينيان، آقاى مصطفى فتاحى و خانم مريم نجاتالهى كه در اين يزوهش همكارى كردهاند، كمال تشكر إنى و قدردانى را داريم. - ماته

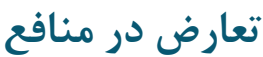

در اين مطالعه تضاد منافع وجود ندارد.
زيروبالانس يزوهش ما سديم اصلاح شد. اين يزوهش نشان مى دهد مدت زمان جداشدن از تهوية مكانيكى و اقامت در

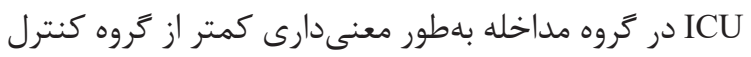

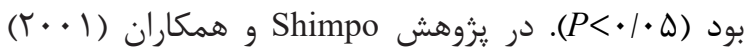

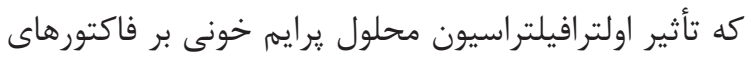

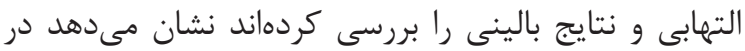

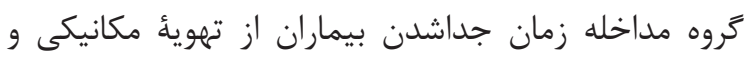

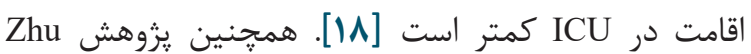

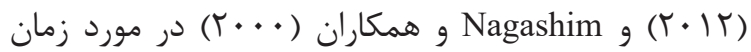

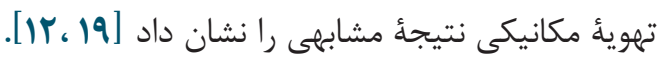

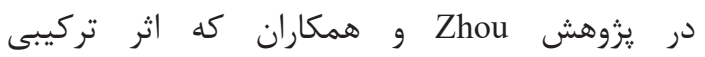
اولترافيلتراسيون را روى شيرخواران انجام داده بودند نتايج مخالف اين يزوهش، در زمينهُ مدت زمان تهوية مكانيكى و و

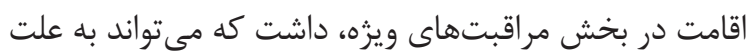

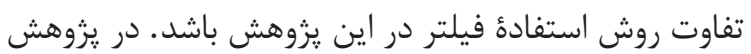
Zhou در حالى كه در اين يزوهش، از همان ابتدا، براى اصلاح

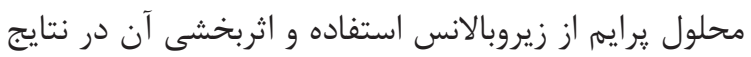

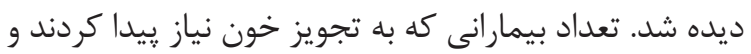

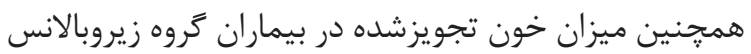

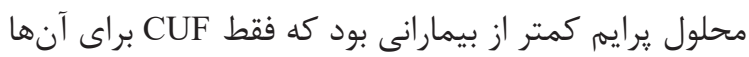

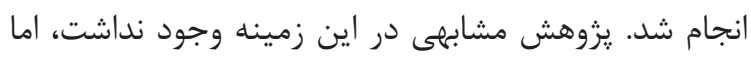
Journois

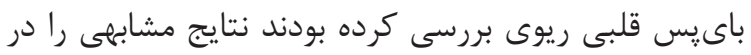

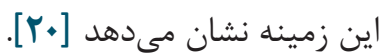
اطلاعات بهدستآمده از روند تغييرات نمونه شريانى (PH, Na, K, Cl, Hb, HCT, BE, BS HCO3) اين يزوهش نشان مىدهد كه در زمانهاى قبل از عمل، بعد

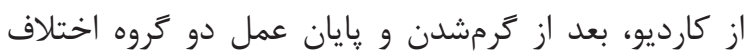

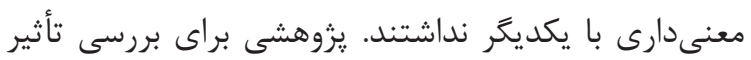

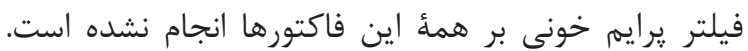
براى بررسى بيشترين اثر محلول برايم، نمونهُ خون بايد در

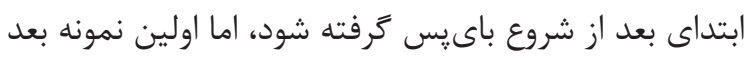
از كارديو كرفته شد كه اين مى بواند عامل مداخله كرى بـ باشد. از عوامل مداخلهَر ديخر به حجم ساكشنى كه از فيلد جراحى وارد مخزن وريدى مى شود و تزريق مقادير متفاوت

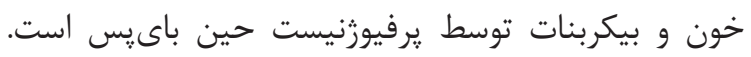

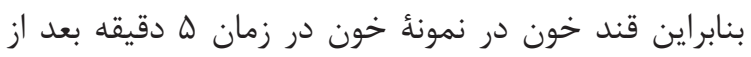

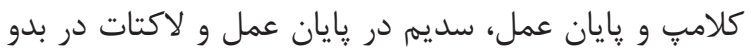
يذيرش در ICU در كروه مداخله باطور معنى دارى كمتر بود 


\section{References}

1. Ashraf S, Tian Y, Zacharrias S, Cowan D, Martin P, Watterson K. Effects of cardiopulmonary bypass on neonatal and paediatric inflammatory profiles. European journal of cardio-thoracic surgery. 1997; 12(6):862-868.

2. Gravlee GP, Davis RF, Hammon J, Kussman B. Cardiopulmonary Bypass and Mechanical Support: Principles and Practice. Lippincott Williams \& Wilkins; 2015.

3. Huang H, Yao T, Wang W, Zhu D, Zhang W, Chen $\mathrm{H}$, et al. Continuous ultrafiltration attenuates the pulmonary injury that follows open heart surgery with cardiopulmonary bypass. The Annals of thoracic surgery. 2003; 76(1):136-140.

4. Ranucci M, Carlucci C, Isgrò $G$, Boncilli A, De Benedetti D, De la Torre T, et al. Duration of red blood cell storage and outcomes in pediatric cardiac surgery: an association found for pump prime blood. Critical care. 2009; 13(6):R207.

5. Osthaus WA, Sievers J, Breymann T, Suempelmann R. Bicarbonate buffered ultrafiltration leads to a physiologic priming solution in pediatric cardiac surgery. Interactive cardiovascular and thoracic surgery. 2008; 7(6):969-972.

6. Crosby ET. Perioperative haemotherapy: II. Risks and complications of blood transfusion. Canadian journal of anaesthesia. 1992; 39(8):822-837.

7. Wang MJ, Chiu S, Hsu CM, Wang CM, Lin PL, Chang CI, et al. Efficacy of ultrafiltration in removing inflammatory mediators during pediatric cardiac operations. The Annals of thoracic surgery. 1996; 61(2):651-656.

8. Garg P, Bishnoi AK, Patel K, Wadhawa V, Surti J, Solanki A, et al. Hemodiafiltration: A Technique for Physiological Correction of Priming Solution in Pediatric Cardiac Surgery: An In Vitro Study. Artificial organs. 2017; 41(8):773-778.

9. McLellan BA, Reid SR, Lane PL. Massive blood transfusion causing hypomagnesemia. Critical care medicine. 1984; 12(2):146-147.

10. Wilson R, Binkley L, Sabo JF, Wilson J, Munkarah M, Dulchavsky S, et al. Electrolyte and acid-base changes with massive blood transfusions. The American Surgeon. 1992; 58(9):535-544.

11. Biffl WL, Moore EE, Offner PJ, Ciesla DJ, Gonzalez RJ, Silliman CC. Plasma from aged stored red blood cells delays neutrophil apoptosis and primes for cytotoxicity: abrogation by poststorage washing but not prestorage leukoreduction. Journal of Trauma and Acute Care Surgery. 2001; 50(3):42632.

12. Nagashima M, Imai Y, Seo K, Terada M, Aoki M, Shin'oka T, et al. Effect of hemofiltrated whole blood pump priming on hemodynamics and respiratory function after the arterial switch operation in neonates. The Annals of thoracic surgery. 2000; 70(6):1901-1906.

13. Gholampour Dehaki M, Niknam S, Azarfarin $\mathrm{R}$, Bakhshandeh $\mathrm{H}$, Mahdavi M. Zero-Balance Ultrafiltration of Priming Blood Attenuates Procalcitonin and Improves the Respiratory Function in Infants After Cardiopulmonary Bypass: A Randomized Controlled Trial. Artificial organs. 2019; 43(2):167-172.

14. Matata BM, Scawn N, Morgan M, Shirley S, Kemp $\mathrm{I}$, Richards S, et al. A single-center randomized trial of intraoperative zero-balanced ultrafiltration during cardiopulmonary bypass for patients with impaired kidney function undergoing cardiac surgery. Journal of cardiothoracic and vascular anesthesia. 2015; 29(5):1236-1247.

15. Kozik DJ, Tweddell JS. Characterizing the inflammatory response to cardiopulmonary bypass in children. The Annals of thoracic surgery. 2006; 81(6):S2347-S2354.

16. Ugaki S, Honjo O, Kotani Y, Nakakura M, Douguchi T, Oshima Y, et al. Ultrafiltration of priming blood before cardiopulmonary bypass attenuates inflammatory response and maintains cardiopulmonary function in neonatal piglets. Asaio Journal. 2009; 55(3):291-295.

17. Zhou G, Feng Z, Xiong H, Duan W, Jin Z. A combined ultrafiltration strategy during pediatric cardiac surgery: a prospective, randomized, controlled study with clinical outcomes. Journal of cardiothoracic and vascular anesthesia. 2013; 27(5):897-902.

18. Shimpo H, Shimamoto A, Sawamura Y, Fujinaga $\mathrm{K}$, Kanemitsu S, Onoda K, et al. Ultrafiltration of the priming blood before cardiopulmonary bypass attenuates inflammatory response and improves postoperative clinical course in pediatric patients. Shock (Augusta, Ga). 2001; 16:51-4.

19. Zhu X, Ji B, Wang G, Liu J, Long C. The effects of zero-balance ultrafiltration on postoperative recovery after cardiopulmonary bypass: a metaanalysis of randomized controlled trials. Perfusion. 2012; 27(5):386-392.

20. Journois D, Israel-Biet D, Pouard P, Rolland B, Silvester W, Vouhe P, et al. High-volume, zero-balanced hemofiltration to reduce delayed inflammatory response to cardiopulmonary bypass in children. Anesthesiology: The Journal of the American Society of Anesthesiologists. 1996; 85(5):965-976. 